\title{
Chemical composition and antibacterial activities of seven Eucalyptus species essential oils leaves
}

\author{
Khaled Sebei $^{{ }^{*}}$, Fawzi Sakouhi ${ }^{1}$, Wahid Herchi ${ }^{1}$, Mohamed Larbi Khouja ${ }^{2}$ and Sadok Boukhchina ${ }^{1}$
}

\begin{abstract}
Background: In this paper, we have studied the essential oils chemical composition of the leaves of seven Eucalyptus species developed in Tunisia. Eucalyptus leaves were picked from trees growing in different arboretums in Tunisia. Choucha and Mrifeg arboretums located in Sedjnene, region of Bizerte (Choucha: E. maideni, E. astrengens et E. cinerea; Mrifeg : E. leucoxylon), Korbous arboretums located in the region of Nabeul, North East Tunisia with sub-humid bioclimate, (E. lehmani), Souiniet-Ain Drahem arboretum located in region of Jendouba (E. sideroxylon, E. bicostata). Essential oils were individually tested against a large panel of microorganisms including Staphylococcus aureus (ATCC 6539), Escherichia coli (ATCC 25922), Enterococcus faecalis (ATCC29212), Listeria ivanovii (RBL 30), Bacillus cereus (ATCC11778).

Results: The yield of essential oils ranged from 1.2\% to 3\% (w/W) for the different Eucalyptus species. All essential oils contain a-pinene, 1,8-cineol and pinocarveol-trans for all Eucalyptus species studied. The 1,8-cineol was the major compound in all species (49.07 to 83.59\%). Diameter of inhibition zone of essential oils of Eucalyptus species varied from 10 to $29 \mathrm{~mm}$. The largest zone of inhibition was obtained for Bacillus cereus (E. astrengens) and the lowest for Staphylococcus aureus (E. cinerea). The essential oils from E. maideni, E. astrengens, E. cinerea (arboretum of Bizerte), E. bicostata (arboretum of Aindraham) showed the highest antibacterial activity against Listeria ivanovii and Bacillus cereus. Conclusion: The major constituents of Eucalyptus leaves essential oils are 1,8-cineol (49.07 to 83.59\%) and a-pinene (1.27 to 26.35\%). The essential oils from E. maideni, E. astrengens, E. cinerea, E. bicostata showed the highest antibacterial activity against Listeria ivanovii and Bacillus cereus, they may have potential applications in food and pharmaceutical products.
\end{abstract}

Keywords: Eucalyptus, Essential oil, Antibacterial activity, a-pinene

\section{Background}

Eucalyptus, a native genus from Australia, belongs to Myrtaceae family and comprises about 900 species and subspecies, it is one of the world's most important and most widely planted genera [1-4]. It has been introduced worldwide, including in Tunisia and mainly cultivated for its timber, pulp and essential oils that present medicinal properties and therapeutic uses [5]. In recent decades, the essential oils and their components of plants have been of great interest as they have been the sources of natural products [6]. The value of Eucalyptus oil for medicinal purposes is based largely on the content of a particular oil constituent: 1,8-cineole (cineole or eucalyptol)

\footnotetext{
* Correspondence: k.sebei@yahoo.fr

'Laboratoire de Biochimie des Lipides et Interactions avec les

Macromolécules, Faculté des Sciences de Tunis, Université de Tunis-El-Manar, Elmanar 2092, Tunis, Tunisia

Full list of author information is available at the end of the article
}

[7]. Hot water extracts of dried leaves of Eucalyptus citriodora are traditionally used as analgesic, anti-inflammatory and antipyretic remedies for the symptoms of respiratory infections, such as cold, flu, and sinus congestion ([8], Eucalyptus camaldulensis and Eucalyptus urophylla are also known to contain bioactive products that showed antibacterial [9], antifungal [10], analgesic and anti-inflammatory effects [8], antioxidative and antiradical [11] activities. Various studies showed that differences in the yield and composition of the essential oils were influenced by the time of harvest, moreover, for Eucalyptus genus, the amount and composition of leaf oil may vary seasonally and diurnally for some plants, depending on environmental conditions [12].

The objectives of the present study are to determine the chemical composition of the essential oils of seven common Tunisian Eucalyptus species, namely E. lehmani; E. leucoxylon; E. astrengens; E. cinerea; E. maideni; E. 
sideroxylon; E. bicostata. The study also aims at investigating the antibacterial properties against some of the common pathogens bacteria. In addition, the study determines the influence of growth conditions on the chemical composition and antibacterial properties of the essential oils of Eucalyptus species.

\section{Results and discussion}

\section{Eucalyptus essential oil yields}

The yield of essential oils ranged from $1.2 \%$ to $3 \%(\mathrm{w} / \mathrm{w})$ for the different Eucalyptus species (Table 1). The highest yield was obtained from E. cinerea and E. sideroxylon (3\%), followed by E. lehmani (2.8\%), while E. astrengens gave the lowest yield at $1.2 \%$. According to these results, we confirmed that there is no relationship between region and Eucalyptus essential oil yield. In fact, species from the same region show different yields (E. leucoxylon; $E$. astrengens; E. cinérea) while species from different regions have almost the same yield.

Some parameters can influence yields such as leaves age [13], the harvest date [14], geographical origine [15], distillation method [16,17]' Ben Jemàa et al., [12] reported that essential oil yields varied according to Eucalyptus species and seasons and for all species studied, (E. camaldulensis, E. astringens, E. leucoxylon, E. lehmannii and E. rudis) high yields were obtained from leaves collected at the summer season though $E$. astringens gave rather constant yields during winter $(1.23 \%$ for spring and $1.1 \%$ for winter).

\section{Composition of the essential oils}

The chemical composition of the essential oils extracted from Eucalyptus species (E. maideni; E. astrengens; $E$. cinerea; E. leucoxylon; E. lehmani; E. sideroxylon; E. bicostata) is presented in Table 2. All essential oils contain $\alpha$-pinene, 1,8-cineol and pinocarveol-trans for all Eucalyptus species studied. The 1,8-cineol was the major compound in all species. The essential oil composition of the Eucalyptus species from the region of Bizerte showed that all of them contained 1,8-cineole, the highest content was obtained from E. maideni (83.59\%) followed by E. cinerea and E. lehmani (respectively $79.18 \%$ and $49.07 \%$ ), while E. astrengens gave the lowest rate (60.01\%). Although these species are from the same region, they show differences in the levels of some essential oil compounds. This may be due to genetic effects. Essential oils extracted from species from Aindraham arboretum (E. sideroxylon and

Table 1 Eucalyptus essential oil yield at the different regions of Tunisia

\begin{tabular}{llllllll}
\hline & E.m & E.a & E.c & E.le & E.I & E.s & E.b \\
\hline Yield of essential oil (\%) & 1.5 & 1.2 & 3 & 1.6 & 2.8 & 3 & 2
\end{tabular}

E.m : E. maideni; E.a : E. astrengens; E.c : E. cinerea; E.le : E. leucoxylon; E.l : E. lehmani; E.s : E. sideroxylon; E.b : E. bicostata.
E. bicostata) have the same 1,8 cineole level and the species from Korbous arboretum (E. lehmani) have the lowest rate of 1,8-cineole (49.07\%) and the highest level of $\alpha$-pinene (26.35\%). We could identify other compounds of relatively high rates such as globulol and pinacarvone. Ben jemâa et al., [12] reported that GC and GC-MS analyses showed that chemical composition varied with Tunisian Eucalyptus species and seasons. The five essential oils contained 1,8-cineole, $\alpha$-pinene, and $\alpha$-terpineol as major common compounds. The essential oils of twenty Eucalyptus species harvested from North West and North of Tunisia were studied and the authors identified, by GC and GC/MS, eighteen major compounds and the main ones were 1,8-cineol followed by $\alpha$-pinene, p-cymene, borneol, cryptone, spathulenol, viridiflorol and limonene. The authors showed that main components were oxygenated monoterpenes, among them 1,8-cineol which was the major one in leaf essential oils of ten species, followed by trans-pinocarveol and $\alpha$-terpineol. The oxygenated sesquiterpenes were the second major class represented essentially by borneol, spathulenol, viridiflorol and globulol; the third major class was the monoterpene hydrocarbons constituted by a high level of $\alpha$-pinene, $p$ cymene and limonene [16].

In Taiwanian Eucalyptus species, a total of 20 compounds amounting to $97.58 \%$ in the E. camaldulensis leaf essential oil were identified. Among these $81.41 \%$ were monoterpene hydrocarbons, $12.55 \%$ were oxygenated monoterpenes, and it also contained $0.50 \%$ sesquiterpene hydrocarbons and $3.12 \%$ oxygenated sesquiterpenes. The major constituents in the E. camaldulensis leaf essential oil were $\alpha$-pinene $(22.52 \%)$, p-cymene $(21.69 \%)$, aphellandrene (20.08\%), 1,8-cineole (9.48\%), c-terpinene (9.36\%), and limonene (4.56\%) [18]. For Eucalyptus species, many factors may influence monoterpene emissions, especially seasonal and diurnal emission activity cycles [19].

\section{Antibacterial activity}

According to the zone diameter inhibition (zdi) values expressed in $\mathrm{mm}$, results were ranked as follows: not sensitive (-) for zone diameters equal to $8 \mathrm{~mm}$ or below; sensitive $(+)$ for zone diameters between 8 and $14 \mathrm{~mm}$, very sensitive $(++)$ for zone diameters between 14 and $20 \mathrm{~mm}$ and extremely sensitive $(+++)$ for zone diameters equal or larger than $20 \mathrm{~mm}[17,20,21]$. The results revealed that the essential oils showed antibacterial activity with varying magnitude and depending on the size of inoculums. Diameter of inhibition zone of essential oils of eucalyptus species varied from 10 to $29 \mathrm{~mm}$ (Table 3 ). The largest zone of inhibition was obtained for Bacillus cereus (E. astrengens) and the lowest for Staphylococcus aureus (E. cinerea). The essential oils from $E$. maideni, E. astrengens, E. cinerea (arboretum of Bizerte), E. bicostata (arboretum of Aindraham) showed the highest 
Table 2 Chemical composition of essential oil from Eucalyptus leaves

\begin{tabular}{|c|c|c|c|c|c|c|c|}
\hline Compounds (\%) & E.m & E.a & E.c & E.le & E.I & E.s & E.b \\
\hline a- pinene & 1.27 & 6.96 & 4.08 & 5.85 & 26.35 & 5.81 & 2.16 \\
\hline 1,8-cineol & 83.59 & 60.01 & 79.18 & 77.76 & 49.07 & 80.75 & 81.29 \\
\hline Terpineol alpha & - & - & 2.20 & - & 3.51 & 2.45 & - \\
\hline Cymene P & - & 2.31 & - & - & 2.42 & - & - \\
\hline Terpinene gamma & - & - & - & 2 & 1,58 & - & - \\
\hline Trans-Pinocarveol & 3.40 & 8.92 & 2.07 & 3.23 & 1.59 & 1 & 4.49 \\
\hline Terpinyl acetate alpha & - & - & 5.43 & & 5.64 & 2.30 & - \\
\hline globulol & 3.61 & 3.74 & - & 1.42 & 1.01 & - & 1.81 \\
\hline Limonene & - & - & - & 1.33 & - & 3.32 & - \\
\hline Pinacarvone & 1.28 & 4.70 & - & 1.15 & - & - & 3.93 \\
\hline Guaiene & - & 1.33 & - & - & - & - & - \\
\hline Spathulenol & - & 1.15 & - & - & - & - & - \\
\hline Mentha -1(7),8-Dien-2-ol trans $P$ & - & - & 1.09 & - & - & - & 1.03 \\
\hline Others & 6.85 & 10.88 & 5.95 & 7.26 & 8.8 & 4.62 & 5.29 \\
\hline
\end{tabular}

E.m : E. maideni; E.a : E. astrengens; E.c : E. cinérea; E.le : E. leucoxylon; E.I : E. lehmani; E.s : E. sideroxylon; E.b : E. bicostata.

antibacterial activity against Listeria ivanovii and Bacillus cereus.

\section{Conclusion}

The Eucalyptus species investigated in the present study show a large variation in their chemical composition. The major constituents of Eucalyptus leaves essential oils are 1,8 -cineol (49.07 to $83.59 \%)$ and $\alpha$-pinene (1.27 to $26.35 \%)$.

The essential oils from E. maideni, E. astrengens, E. cinerea, E. bicostata showed the highest antibacterial activity against Listeria ivanovii and Bacillus cereus, they may have potential applications in food and pharmaceutical products.

\section{Methods}

\section{Collection of plant material}

Eucalyptus leaves were picked from trees growing in different arboretums in Tunisia: Choucha and Mrifeg arboretums located in Sedjnene, region of Bizerte (Choucha: E. maideni, E. astrengens and E. cinerea; Mrifeg: E. leucoxylon), Korbous arboretum located in the region of Nabeul, (E. lehmani), Souiniet-Ain Drahem arboretum located in the region of Jendouba (E. sideroxylon, E. bicostata). The leaves were stored at a dry place for fifteen days. Specimens were identified at the Regional Station of the National Institute of Research in Farming Studies, Waters and Forests (INRGREF).

\section{Isolation of the essential oils}

One hundred grams of dried leaves were submitted to water distillation (500 mL of water) for 3 hours, using a Clevenger-type apparatus. The obtained essential oils were dried over anhydrous sodium sulphate and after filtration, stored at 4 to $7^{\circ} \mathrm{C}$ until use. The extraction yield was calculated using the following formula: yield = $(\mathrm{VEO} \times 100) / D . M(D . M$ : dry material; VEO: volume of essential oil).

Gas chromatography analysis/mass spectrometry analysis The GC analyses were accomplished with a HP-5890 Series II instrument equipped with HP-WAX and HP-5 capillary columns (both $30 \mathrm{~m} \times 0.25 \mathrm{~mm}, 0.25 \mathrm{~mm}$ film thickness), working with the following temperature program: $60^{\circ} \mathrm{C}$ for $10 \mathrm{~min}$, ramp of $5^{\circ} \mathrm{C} / \mathrm{min}$ up to $220^{\circ} \mathrm{C}$; injector and detector temperatures $250^{\circ} \mathrm{C}$; carrier gas

Table 3 Antibacterial activity of essential oil of Eucalyptus species

\begin{tabular}{|c|c|c|c|c|c|c|c|}
\hline Strains & E.m & E.a & E.C & E.le & E.I & E.s & E.b \\
\hline Listeria ivanovii (RBL30) & $25 \mathrm{~mm}+++$ & $26 \mathrm{~mm}+++$ & $24 \mathrm{~mm}+++$ & $12 \mathrm{~mm}+$ & $11 \mathrm{~mm}+$ & $20 \mathrm{~mm}++$ & $28 \mathrm{~mm}+++$ \\
\hline Escherichia coli (ATCC25922) & $15 \mathrm{~mm}++$ & $15 \mathrm{~mm}++$ & $16 \mathrm{~mm}++$ & $18 \mathrm{~mm}++$ & $20 \mathrm{~mm}++$ & $14 \mathrm{~mm}+$ & -- \\
\hline Staphylococcus aureus (ATCC6533) & -- & $13 \mathrm{~mm}+$ & $10 \mathrm{~mm}+$ & $11 \mathrm{~mm}+$ & $16 \mathrm{~mm}++$ & $12 \mathrm{~mm}+$ & $15 \mathrm{~mm}++$ \\
\hline Enterococcus faecalis (ATCC29212) & $11 \mathrm{~mm}+$ & $12 \mathrm{~mm}+$ & $12 \mathrm{~mm}+$ & $12 \mathrm{~mm}+$ & $12 \mathrm{~mm}+$ & $11 \mathrm{~mm}+$ & $10 \mathrm{~mm}+$ \\
\hline Bacillus cereus (ATCC11778) & $25 \mathrm{~mm}+++$ & $29 \mathrm{~mm}+++$ & $21 \mathrm{~mm}+++$ & $16 \mathrm{~mm}++$ & $17 \mathrm{~mm}++$ & $15 \mathrm{~mm}++$ & $27 \mathrm{~mm}+++$ \\
\hline
\end{tabular}

Not sensitive (-) for zone diameters equal to $8 \mathrm{~mm}$ or below; Sensitive (+) for zone diameters between 8 and $14 \mathrm{~mm}$, Very sensitive (++) for zone diameters between 14 and $20 \mathrm{~mm}$, Extremely sensitive $(+++)$ for zone diameters equal or larger than $20 \mathrm{~mm}$.

E.m : E. maideni; E.a : E. astrengens; E.c : E. cinérea; E.le : E. leucoxylon; E.I : E. lehmani; E.s : E. sideroxylon; E.b : E. bicostata. 
nitrogen $(2 \mathrm{~mL} / \mathrm{min})$; detector dual FID; split ratio 1:30; injection of $0.5 \mathrm{~mL}$ ). The identification of the components was performed, for both columns, by comparison of their retention times with those of pure authentic samples and by means of their linear retention indices (l.r.i.) relative to a series of n-hydrocarbons. The relative proportions of the essential oil constituents were percentages obtained by FID peak-area normalization, without using response factors.

For GC/MS detection, an electron ionization system, with ionization energy of $70 \mathrm{eV}$, a scan time of $1.5 \mathrm{~s}$ and mass range 40-300 amu, was used. Helium was the carrier gas at a flow rate of $1.2 \mathrm{~mL} / \mathrm{min}$. Injector and transfer line temperatures were set at 250 and $280^{\circ} \mathrm{C}$, respectively. Oven program temperature was the same with GC analysis. Diluted samples $(1 / 100$ in hexane, $\mathrm{v} / \mathrm{v})$ of $1.0 \mu \mathrm{l}$ were injected manually and in the splitless mode. The identification of the compounds was based on mass spectra (compared with Wiley 275.L, 6th edition mass spectral library) or with authentic compounds and confirmed by comparison of their retention indices either with those of authentic compounds or with data published in the literature as described by Adams [22]. Further confirmation was done from Kovats Retention Index data generated from a series of $\mathrm{n}$-alkanes retention indices (relative to C9-C28 on the BP-1).

\section{Antibacterial activity detection}

Essential oils were individually tested against a panel of microorganisms including Staphylococcus aureus (ATCC 6539), Escherichia coli (ATCC 25922), Enterococcus faecalis (ATCC29212), Listeria ivanovii (RBL 30), Bacillus cereus (ATCC11778). All strains were obtained from Institut Pasteur de Tunis. The Bacteriological agar was from Biokar Diagnostics (Beauvais, France). Nutrient broth (NB) was from Difco (Becton Dickinson, Le Pont de Claix, France). All the other media, used in this study, were manufactured by Biorad (Marnes-La Coquette, France) and Merck. Antibacterial activity is revealed by growth inhibition in the strains to test. This activity is observed in solid medium. In the present work, we used well diffusion method described by Perez et al., [23].

\section{Statistical analysis}

The data (three replicates) were statistically evaluated using the JMP SAS version 12.6 software (Statistical Analysis System). (SAS, Institute INC, Box 8000, Cary, North Carolina 27511, USA).

\section{Competing interests}

The authors declare that they have no competing interests.

\section{Authors' contributions}

FS carried out the analysis of essential oils by GC-MS. WH drafted the manuscript. MLK identifies specimens of Eucalyptus species. BS helped to draft the manuscript. All authors read and approved the final manuscript.

\section{Acknowledgements}

We are very grateful to Guido Flamini (Dipartimento di Chimica Bioorganica e Biofarmacia, Facolta di Farmacia, Universita di Pisa. Italy) for the identification of essential oils.

\section{Author details}

${ }^{1}$ Laboratoire de Biochimie des Lipides et Interactions avec les

Macromolécules, Faculté des Sciences de Tunis, Université de Tunis-El-Manar, Elmanar 2092, Tunis, Tunisia. ${ }^{2}$ Laboratoire d'Ecologie, INRGREF, B.P10, Ariana 2080, Tunisia.

Received: 12 October 2014 Accepted: 7 January 2015

Published: 19 January 2015

\section{References}

1. Gilles M, Zhao J, An M, Agboola S. Chemical composition and antimicrobial properties of essential oils of three Australian Eucalyptus species. Food Chem. 2010;119:731-7.

2. Hakki Z, Cao B, Heskes AM, Goodger JQD, Woodrow IE, Williams SJ. Synthesis of the monoterpenoid esters cypellocarpin C and cuniloside B and evidence for their widespread occurrence in Eucalyptus. Carb Res. 2010;345:2079-84.

3. Tyagi AK, Malik A. Antimicrobial potential and chemical composition of Eucalyptus globulus oil in liquid and vapour phase against food spoilage microor-ganisms. Food Chem. 2011;126:228-35.

4. Pereiraa V, Diasb C, Vasconcelosa MC, Rosaa E, Saavedra MJ. Antibacterial activity and synergistic effects between Eucalyptus globulus leaf residues (essential oils and extracts)and antibiotics against several isolates of respiratory tractinfections (Pseudomonas aeruginosa). Ind Crop Prod. 2014:52:1-7.

5. Ben Hassine D, Abderrabba M, Yvon Y, Lebrihi A, Mathieu F, Couderc F, et al. Chemical composition and in vitro evaluation of the antioxidant and antimicrobial activities of Eucalyptus gillii essential Oil and extracts. Molecules. 2012;17(8):9540-58.

6. Wang W, Wu N, Zu YG, Fu YJ. Antioxidative activity of Rosmarinus officinalis L. essential oil compared to its main components. Food Chem. 2008;108:1019-22.

7. Goodger JQD, Woodrow IE. Selection gains for essential oil traits using micropropagation of Eucalyptus polybractea. For Ecol Manag. 2008;255(10):3652-8.

8. Silva J, Abebe W, Sousa SM, Duarte VG, Machado MIL, Matos FJA. Analgesic and anti-inflammatory effects of essential oils of Eucalyptus. J Ethnopharmacol. 2003;89:277-83.

9. Cimanga K, Kambu K, Tona L, Apers S, De Bruyne T, Hermans N, et al. Correlation between chemical composition and antibacterial activity of essential oils of some aromatic medicinal plants growing in the Democratic Republic of Congo. J Ethnopharmacol. 2002;79(2):213-20.

10. Su YC, Ho CL, Wang El, Chang ST. Antifungal activities and chemical compositions of essential oils from leaves of four eucalyptus. Taiwan J For Sci. 2006;21:49-61.

11. Siramon P, Ohtani Y. Antioxidativ e and antiradical activities of Eucalyptus camaldulensis leaf oils from Thailand. J Wood Sci. 2007;53:498-504.

12. Ben Jemâa JM, Haouel S, Bouaziz M, Khouja ML. Seasonal variations in chemical composition and fumigant activity of five Eucalyptus essential oils against three moth pests of stored dates in Tunisia. J Stored Prod Res. 2012:48:61-7.

13. Chennoufi R, Morizur J, Richard H, Sandret F. Study of Eucalyptus globules essential oils from Morocco (young and adult leaves). Rivista Italiana EPPOS. 1980;62:353-7.

14. Zrira S, Elamrani A, Benjilali B. Chemical composition of the essential oil of Pistacia lentiscus L. from Morocco-a seasonal variation. Flavour Fragr J. 2003;18(6):475-80

15. Zrira S, El Khirani F, Benjilali B. Huiles essentielles de six espèces xérophyles d'Eucalyptus: effet du milieu sur les rendements et la èompositionchimique. Revue Marocaine des Sciences Agronomiques et Vétérinaires. 1994;14(1):5-9.

16. Elaissi A, Hadj Salah K, Mabrouk S, Khouja ML, Chemli R, Harzallah-Skhiri F. Antibacterial activity and chemical composition of 20 Eucalyptus species'essential oils. Food Chem. 2011;129:1427-34.

17. Elaissi A, Rouis Z, Mabrouk S, Bel Haj Salah K, Aouni M, Larbi Khouja M, et al. Correlation between chemical composition and antibacterial activity of 
essential oils from fifteen Eucalyptus species growing in the Korbous and Jbel Abderrahman Arboreta (North East Tunisia). Molecules. 2012;17(30):44-57.

18. Cheng SS, Huang CG, Chen YJ, Yu JJ, Chen WJ, Chang ST. Chemical compositions and larvicidal activities of leaf essential oils from two eucalyptus species. Bioresour Technol. 2008;99(9):3617-22.

19. He C, Murray F, Lyons T. Monoterpene and isoprene emissions from 15 Eucalyptus species in Australia. Atmos Environ. 2000;34:645-55.

20. Ponce AG, Fritz R, Del Valle CE, Roura SI. Antimicrobial activity of essential oils on native microbial population of organic Swiss Chard. Lebenson Wiss Technol. 2003;36:679-84.

21. Schroeder MP, Messing AM. Methods for comparing the antibacterial activity of essential oils and other aqueous insoluble compounds. Bull Nat Formulary Comm. 1949;17:213-8.

22. Adams R. Essential oil components by Quadrupole GC/MS. Carol Stream, IL, USA: Allured Publishing Corp; 2001

23. Perez C, Pauli M, Bazerque P. An antibacterial assay by agar well diffusion method. Acta Bio Et Med Exp. 1990;15:113-5.

doi:10.1186/0717-6287-48-7

Cite this article as: Sebei et al: Chemical composition and antibacterial activities of seven Eucalyptus species essential oils leaves. Biological Research 2015 48:7.

\section{Submit your next manuscript to BioMed Central and take full advantage of:}

- Convenient online submission

- Thorough peer review

- No space constraints or color figure charges

- Immediate publication on acceptance

- Inclusion in PubMed, CAS, Scopus and Google Scholar

- Research which is freely available for redistribution 